\title{
Optimal Placement of Distributed Generators in Radial Distribution System for Reducing the Effect of Islanding
}

\author{
Narayanan. ${ }^{\dagger}$, Shahbaz A. Siddiqui* and Manoj Fozdar**
}

\begin{abstract}
The present trend of increasing the penetration levels of Distributed Generator (DG) in the distribution network has made the issue of Islanding crucial for the reliable operation of the network. The islanding, if not detected early may lead to the collapse of the system as it can drive the distribution system to the cascaded failure. In this paper, an extensive study of the effect of DG placement and sizing is performed by dividing the system into different zones to obtain a reduced effect of islanding. The siting and sizing of DG is carried out to improve the overall voltage profile or/and reduction in active power loss using two stage Genetic Algorithm (GA). In the first stage a basic knockout selection is considered and the best population is taken for next stage, where roulette selection for crossover and mutation is performed for optimal placement and sizing of DGs. The effect of the islanding, due to load variations is reduced by optimal siting and sizing of DG. The effectiveness of the proposed scheme is tested on the IEEE 33 and 69 radial bus systems and the results obtained are promising.
\end{abstract}

Keywords: Distributed generation, Penetration level, Islanding, Voltage stability, Active power loss, Genetic algorithm

\section{Introduction}

Distributed Generation (DG) is an electric power source connected directly to the distribution network. The various definitions and technologies are described in $[1,2]$. DG plays a crucial role for the security, reliability and efficiency of the present day power system [3]. The importance of the DG units in the network is more profound with the increased emphasis on green energy technology and environmental concerns.

Various schemes using different methods have been proposed in the literature for the optimal placement of the DG units in the network for overall voltage profile or/and reduction in active power loss [4-8]. A comprehensive analysis of methods and models for optimal placement of DG units is given in [9]. The impact of DG penetration and siting has been discussed in [10]. An analysis on improvement of voltage profile, loss minimization, power transfer capability using the continuation power flow method and the impact of DG on voltage stability at sensitive buses is discussed in [11]. An approach for DG planning considering the load growth uncertainties, DG integration, the uncertainty due to volatility of fuel prices are proposed in $[12,13]$. An optimal planning of dispatch-

$\dagger$ Corresponding Author: Department of Electrical Engineering, Malaviya National Institute of Technology, Jaipur, Rajasthan, India. (narayanan.mnit@gmail.com)

* Department of Electrical and Electronics Engineering, Manipal University, Jaipur, Rajasthan, India. (shajju77@gmail.com)

** Department of Electrical Engineering, Malaviya National Institute of Technology, Jaipur, Rajasthan, India. (manojfozdar@rediffmail.com)

Received: December 11, 2014; Accepted: October 21, 2015 able and non-dispatchable DG units for loss reduction, for optimal hourly production, power factor improvement, penetration of DG units using PSO and reduction in annual energy losses are proposed in [14, 15]. A detailed analysis of the network security [16], losses, reliability, voltage improvement [17], loadability enhancement [18, 19], withstanding capacity of the secondary distribution networks [20] in the presence of DG have been reported in literature.

According to IEEE STD 1547-2003 islanding is a situation in which a distribution system becomes electrically isolated from the remainder of the power system due to a fault upstream or any other disturbance and yet continues to be energized by the DG connected to it [21]. The islanding may occur due to internal faults in the system or due to load variations beyond the permissible limits. The islanding detection techniques are broadly classified into Active and Passive techniques [22]. Active islanding detection techniques have smaller non-detection zones (NDZ) than passive techniques. Active methods are not as simple and easy to implement as passive methods [23, 24].The passive scheme makes decisions based on the local measurements of voltage and current signals. The algorithms of this scheme include under/over frequency and voltage, rate-of-change of frequency and power, vector surge and harmonic distortion indices [25]. A comprehensive survey of islanding protection with renewable DG is reported in [26]. The proper placement of DG can aid the intentional islanding process thereby reducing the load shedding [27].

In this paper, a scheme has been proposed to reduce the effect of islanding while improving the overall voltage profile and/or minimizing the active power losses in the 
distribution system. The scheme has been implemented by dividing the system into zones and finding the optimal locations and sizes of DGs in the individual zones using GA. The conventional GA requires a large population size for an optimal solution; it has largely been reduced by a proposed two stage selection method. This method combines the process of a knockout selection and roulette wheel selection. The initial population in the first stage is made up of a vast number of locations and sizes of DGs in the individual selected zones. The roulette wheel is made of $\mathrm{N}$ 1 number of slots, where $\mathrm{N}$ is the number of buses in the second stage. The N-1 best results from the initial best results of the knockout selection are taken for roulette wheel selection and then the process of cross over and mutation are performed. By this, the best individuals with very good fitness are taken into consideration and the convergence is much faster. The proposed method is tested on IEEE-33 and IEEE-69 standard radial distribution test systems. The proposed two stage GA is able to find the best solutions, and the results obtained in reducing the effect of islanding are promising.

\section{Proposed Scheme for Optimal Placement of DG}

The optimal placement and sizing of DG in the network is crucial in the planning stage of any network. The appropriate placement of DG can result in several benefits like reduction of active power losses, increased reliability of the network, improved voltage profile, peak demand shaving [2].

\subsection{Problem formulation}

In the proposed scheme, the objective of siting and sizing of DGs to reduce the effect of islanding by considering the improvement of voltage profile and reduction of active power losses is formulated as:

$$
F=\left(W_{1} * \operatorname{Max}\left[V_{S}\right]\right)+\left(W_{2} * \operatorname{Max}\left[P_{\text {Losses, diff }}\right]\right)
$$

Where $W_{1}$ and $W_{2}$ are the weights assigned to the objective with $W_{1}+W_{2}=1$.

$$
\begin{gathered}
V_{s}=\frac{\sum_{i=1}^{\mathrm{m}} V_{i \text { With } D G}-\sum_{i=1}^{m} V_{i \text { Without } D G}}{\sum_{i=1}^{m} V_{i} \text { Without } D G} * 100 \% \\
P_{\text {Losses,diff }}=\left[\frac{P_{\text {Losses }}-P_{\text {Losses }, D G}}{P_{\text {Losses }}} * 100 \%\right] \\
P_{\text {Losses }}=\sum_{a=1}^{k} P_{a} \\
P_{a}=R_{i} * \frac{\left\{P_{i}^{2}+Q_{i}^{2}\right\}}{\left|V_{i}\right|^{2}}
\end{gathered}
$$

Where $V_{i \text { Without } D G}$ is the voltage at $i^{\text {th }}$ bus without DG, $V_{i \text { With } D G}$ is the voltage at $i^{\text {th }}$ bus with DG, $m$ is the total number of buses in the system, $P_{\text {Losses }}$ is the total active power losses in the system without DG, $P_{\text {Losses, } D G}$ is the total active power in the system with DG, $P_{a}$ is the power loss in the line connecting buses $a$ and $b, k$ is the total number of lines in the system, $R_{i}$ is the resistance of the line connecting adjacent buses, $P_{i}$ is the Active power of the $i^{\text {th }}$ bus, $Q_{i}$ is the Reactive power the $i^{\text {th }}$ bus and $V_{i}$ is the voltage at $i^{\text {th }}$ bus. The following constraints are considered for finding the optimal location and size of DGs

$$
\begin{gathered}
V_{\min } \leq V_{i} \leq V_{\max } \\
0 \leq P_{D G} \leq P_{D} * P L \\
\text { Penetration Level }(P L)=\frac{P_{D G}}{P_{L O A D}} * 100 \%
\end{gathered}
$$

Where $V_{\min }$ is the minimum voltage at any bus, considered as 0.95 p.u. in this work and $V_{\max }$ is the maximum voltage considered as 1.05 (p.u), $P_{D G}$ is the active power supplied by the DG at unity power factor and $P_{D}$ is the total power demand in the network. The total penetration level of all DGs is considered to not exceed $30 \%$ of the total supply to the distribution system [11]. The optimal location and size of the DGs are obtained to reduce the effect of islanding. After placement of DGs by the proposed method there is simultaneous improvement in voltage profile and reduction in losses with the increase in load profile in individual island formed. The output of DGs is assumed to be in either UP or DOWN state without any intermediate state in between.

\subsection{Genetic algorithm}

The placement and sizing of DG in the system is determined using Genetic Algorithm (GA). GA derives its behaviour from a metaphor from the process of Evolution in nature [18]. The advantage of using evolutionary computational technique is the simplicity in approach, robust response to changing circumstances and its flexibility. Therefore, it has been extensively used for various issues like reduction of losses, improvement of voltage profile [29-32].

Selection is the process of choosing two parents from the population for crossing. The tournament selection strategy provides selective pressure by holding a tournament competition among $\mathrm{N}$ individuals. The best individual from the tournament is the one with the highest fitness, which is the winner of $\mathrm{N}$. Roulette selection is one of the traditional GA selection techniques. The principle of roulette selection is a linear search through a roulette wheel with the slots in the wheel weighted in proportion to the individual's fitness values. After the selection (reproduction) process, the population is enriched with better individuals.

Crossover is the process of taking two parent solutions 
and producing from them a child. Mutation recovers the lost genetic materials and prevents the algorithm to be trapped in a local minimum. Elitism is the procedure by which the weakest individual of the current population is replaced by the fittest individual of the immediately preceding population.

The encoding of each parent considered for present study is given as:

\begin{tabular}{|c|c|c|c|c|c|c|c|}
\hline $\begin{array}{c}D G \\
\mathrm{Loc}_{1}\end{array}$ & $\begin{array}{c}D G \\
\mathrm{Loc}_{2}\end{array}$ & $\cdots \ldots$ & $\begin{array}{c}D G \\
\mathrm{Loc}_{n}\end{array}$ & $\begin{array}{c}D G \\
\mathrm{Cap}_{1}\end{array}$ & $\begin{array}{c}\text { DG } \\
\text { Cap } 2\end{array}$ & $\ldots \ldots$ & $\begin{array}{c}\text { DG } \\
\mathrm{Cap}_{n}\end{array}$ \\
\hline
\end{tabular}

Where $\mathrm{n}$ is the number of DGs. $D G L o c_{1}$ is the location of the first DG, $D G L o c_{2}$ is the location of the second DG and so on. $D G \mathrm{Cap}_{1}$ is the capacity of the first DG; $D G$ $\mathrm{Cap}_{2}$ is the location of the second DG and so on.

\section{Proposed Methodology}

The values of the weights are selected depending upon the purpose of the objective function: (a) improving overall voltage profile, (b) reducing total active power losses and (c) simultaneously achieving both (a) and (b). The systems have been divided into different zones for the placement of DG. The number of zones considered for the present study depends upon the number of DGs considered, whereas the location of zones is considered arbitrarily with each zone having one DG.

\subsection{Division of the system into different zones}

\subsubsection{Bus System}

The test system has been analysed for 3 DGs and 4 DGs respectively. For this purpose the system is divided into different zones and the placement of DG is performed.

1) 3 DGs

Zone 1: Bus 2 to Bus 18

Zone 2: Bus 19 to Bus 25

Zone 3: Bus 26 to Bus 33.

2) 4 DGs

Zone 1: Bus 2 to Bus 18

Zone 2: Bus 19 to Bus 22

Zone 3: Bus 23 to Bus 25

Zone 4: Bus 26 to Bus 33.

\subsubsection{Bus System}

The bus system has been analysed for 4 DGs, 5 DGs and 6DGs respectively after dividing the system into different zones.

\section{1) 4 DGs}

Zone 1: Bus 3 to Bus 27, Bus 47 to Bus52 and Bus 66 to Bus 69
Zone 2: Bus 28 to Bus 35

Zone 3: Bus 36 to Bus 46

Zone 4: Bus 53 to Bus 65.

2) 5 DGs

Zone 1: Bus 3 to Bus 27 and Bus 66 to Bus 69

Zone 2: Bus 28 to Bus 35

Zone 3: Bus 36 to Bus 46

Zone 4: Bus 47 to Bus 52

Zone 5: Bus 53 to Bus 65.

3) $6 \mathrm{DGs}$

Zone 1: Bus 3 to Bus 27

Zone 2: Bus 28 to Bus 35

Zone 3: Bus 36 to Bus 46

Zone 4: Bus 47 to Bus 52

Zone 5: Bus 53 to Bus 65

Zone 6: Bus 66 to Bus 69.

\subsection{Proposed algorithm}

The various steps in implementing the proposed two stage selection scheme for placing and sizing of the DGs is summarized as:

i. Read the system data

ii. Initially a vast population size of 500 DGs of different locations and sizes are considered randomly for each zone.

iii. The fitness of the objective is checked for each value and the population is ranked according to the best results arrived for each zone.

iv. The top ranked population of each zone equal to the Number of buses (N) -1 is selected for the next stage.

v. A roulette wheel selection is followed for the crossover and mutation process. Two point crossover is performed with mutation rate as $6 \%$.

vi. The off springs of step $\mathrm{v}$ become the parents for the next generation and step $\mathrm{v}$ is repeated until the convergence is achieved or the maximum generation is reached.

After placement of DGs, the loads of all the buses are increased from base case to $125 \%$ of base load. The load at which islanding occurs is identified along with the vulnerable bus.

\section{Simulation Results}

All simulations are performed in MATLAB 7.10. [33] and PSAT [34]. Three different cases are considered as: case 1 is when $W_{l}=1$ (for voltage stability maximization), case 2 when $W_{1}$ and $W_{2}$ are varied between 0 and 1 for improving voltage profile and reducing active power loss simultaneously, case 3 is when $W_{2}=1$ (for loss minimization). In the present study for case 2, the values of $W_{l}$ is taken as 0.25 for 33 bus system and as 0.75 for 69 bus system 
Table 1. Comparison of results for 33 bus with 3 DGs

\begin{tabular}{c|c|c|c|c|c}
\hline Case & $\begin{array}{c}\text { Minimum voltage in the } \\
\text { system (p.u) }\end{array}$ & $\begin{array}{c}\text { Voltage stability improvement } \\
(\%)\end{array}$ & $\begin{array}{c}\text { Total active power loss } \\
(\mathrm{MW})\end{array}$ & $\begin{array}{c}\text { Reduction in active power } \\
\text { loss (\%) }\end{array}$ & $\begin{array}{c}\text { Islanded } \\
\text { bus }\end{array}$ \\
\hline Without DG & 0.9131 & - & 0.1968 & - & - \\
\hline Case1 & 0.9816 & 4.32 & 0.03895 & 80.26 & 4 \\
\hline Case2 & 0.9813 & 4.31 & 0.03732 & 81.03 & 4 \\
\hline Case3 & 0.9803 & 4.28 & 0.03735 & 81.11 & 4 \\
\hline Existing method [6] & - & 4.32 & 0.0423 & 78.51 & 3 \\
\hline
\end{tabular}

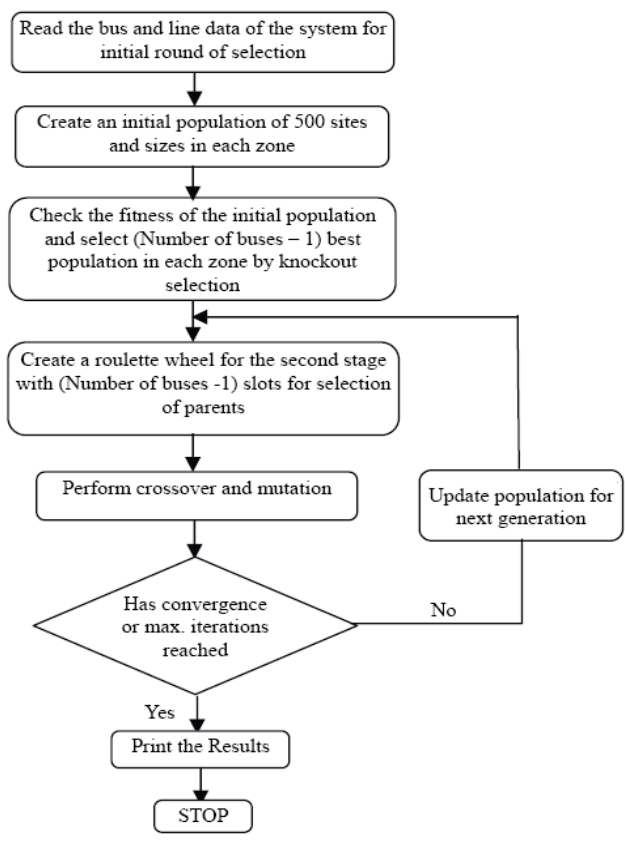

Fig. 1. Flowchart for optimal siting and sizing of DG

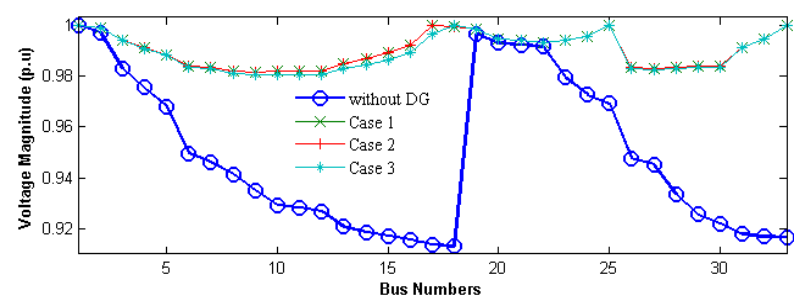

Fig. 2. Comparison of Voltage Profiles of 33 Bus System with 3 DGs and without DG

respectively. After simulating various combinations, the selected values are found to be giving better results. The results obtained from the proposed scheme are presented.

\subsection{Bus system with 3 DGs}

The optimal location of DGs obtained from the proposed scheme is at bus numbers 17,25 and 33 with ratings as $450 \mathrm{~kW}, 380 \mathrm{~kW}, 275 \mathrm{~kW}$ respectively when $W_{1}$ is considered as 1 . When $W_{l}$ is taken as 0 , the optimal location of DGs obtained are at bus number 18, 25 and 33 with ratings as $444 \mathrm{~kW}, 384 \mathrm{~kW}$ and $273 \mathrm{~kW}$ respectively. However, when $W_{1}$ is taken as 0.25 the optimal locations of DGs are found to be same as case $1\left(W_{1}=1\right)$ but the ratings of each DG are

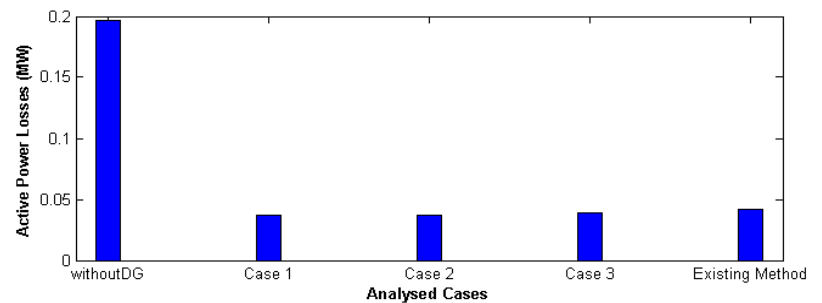

Fig. 3. Comparison of real power losses of 33 bus system with 3 DGs

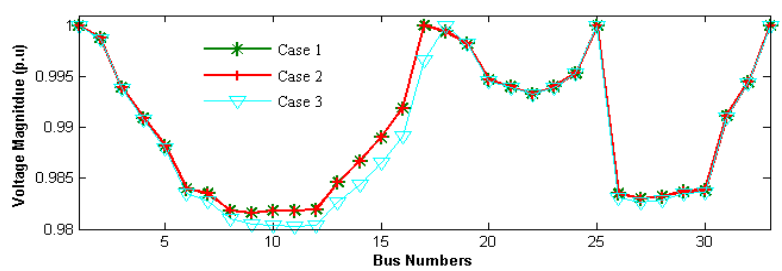

Fig. 4. Comparison of voltage profiles of 33 bus system with effect of DG for different weights

$450 \mathrm{~kW}, 387 \mathrm{~kW}, 275 \mathrm{~kW}$ respectively. It has been observed that the system gets islanded for an overload of $15.25 \%$ at bus 4 forming a main system consisting of buses 1-3,1922,23-25 and an islanded system consisting of buses 418,26-33. However, since the DGs are connected in this island therefore they supply active power reducing the impact of islanding.

From Fig. 2 it is found that when $W_{1}$ is taken as 1 or 0.25 , the overall improvement in voltage stability is almost the same. The minimum voltage in the system is also much improved than when compared in the absence of DG. From Fig. 3 it is found that when $W_{1}$ is taken as 0 , there is marginal improvement in the reduction of losses. It is better to consider case 2 as the best since, it offers a better solution with respect to both voltage stability improvement and reduction in losses. An analysis of all the scenarios is presented in Table 1. From the table, it can be seen that the placement of DG for a multiple objective function gives almost the same result as that of a single objective function. So, it is much beneficial to consider multiple objectives for optimal placement and sizing of DG. The effect of weights on voltage profiles after DG placement in the system can be seen in Fig. 4.

\subsection{3 bus system with 4 DGs}

For this case when 4 DGs are considered in the system 
Table 2. Comparison of results for 33 bus with 4 DGs

\begin{tabular}{c|c|c|c|c|c}
\hline Case & $\begin{array}{c}\text { Minimum voltage in the system } \\
(\mathrm{p} . \mathrm{u})\end{array}$ & $\begin{array}{c}\text { Voltage stability improvement } \\
(\%)\end{array}$ & $\begin{array}{c}\text { Total active power loss } \\
(\mathrm{MW})\end{array}$ & $\begin{array}{c}\text { Reduction in active power } \\
\text { loss }(\%)\end{array}$ & $\begin{array}{c}\text { Islanded } \\
\text { bus }\end{array}$ \\
\hline Without DG & 0.9131 & - & 0.1968 & \\
\hline Case1 & 0.9814 & 4.42 & 0.03753 & - \\
\hline Case2 & 0.9813 & 4.36 & 0.03885 & 82.97 \\
\hline Case3 & 0.9803 & 4.29 & 0.03886 & 8 \\
\hline
\end{tabular}

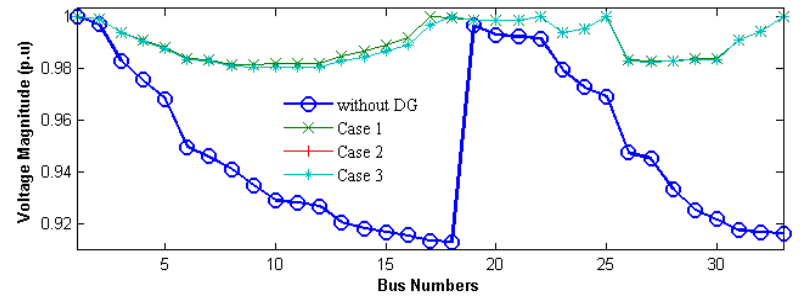

Fig. 5. Comparison of Voltage profiles of 33 bus system with 4 DGs

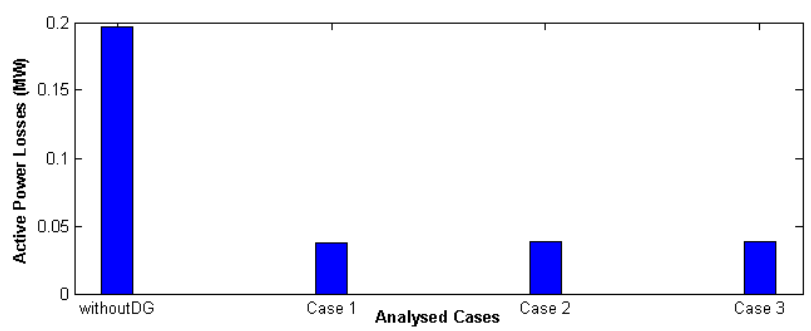

Fig. 6. Comparison of real power losses of 33 bus system with 4 DGs

the optimal location of DGs obtained are at bus numbers $17,22,25$ and 33 with ratings as $450 \mathrm{~kW}, 100 \mathrm{~kW}, 120 \mathrm{~kW}$, $263 \mathrm{~kW}$ respectively for $W_{1}=1$. When $W_{1}$ is considered as 0.25 or 0 the optimal locations of DGs are at buses 18,22 , 25 and 33. The ratings of DG obtained are $450 \mathrm{~kW}, 98 \mathrm{~kW}$, $120 \mathrm{~kW}$ and $272 \mathrm{~kW}$ respectively when $W_{1}$ is taken as 0.25 . When $W_{1}$ is taken as 0 , the ratings of DGs obtained are $447 \mathrm{~kW}, 100 \mathrm{~kW}, 120 \mathrm{~kW}, 274 \mathrm{~kW}$ respectively. The system gets islanded at bus 4 for an overload of $15.25 \%$ forming a main system consisting of buses 1-3,19-22,23-25 and an islanded system consisting of buses 4-18, 26-33. Since the DGs are connected in the islanded network thus they supplies active power in the islanded system and thereby reduces the impact of islanding.

From Fig. 5 and Fig. 6, it can be seen that, when DG is placed for simultaneously improving the voltage profile and reducing the losses, it gives a better result. An analysis of the scenarios is presented in Table 2. From the table it can be seen that the results are much better while considering multiple objective functions rather than a single objective function. However, in all the above cases, the reduction in losses and improvement in voltage stability with the addition of the 4 DG is very marginal. Hence it would be much beneficial to divide the system into 3 zones and place 3 DGs to reduce the cost due to placement of DG. The results have been compared with

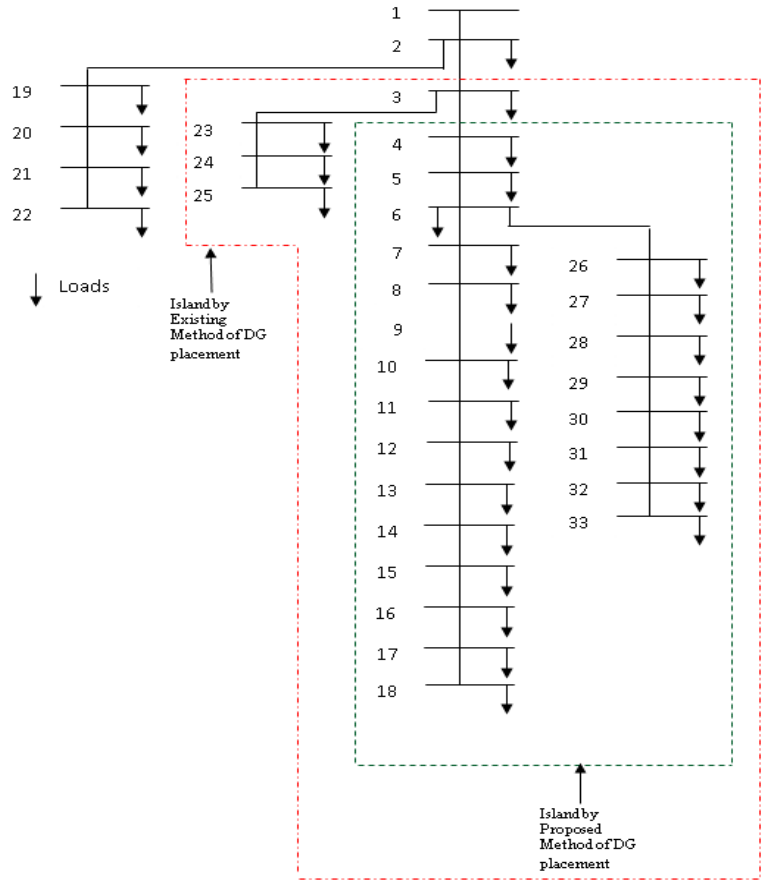

Fig. 7. Formation of Island in 33 Bus System by existing [6] and proposed method of DG placement

existing method [6]. The Fig. 6 shows the islands by the proposed method and existing method. It is observed that in existing method the islanding occurs at bus 3 for same operating conditions. The existing method of DG placement creates an island where the number of loads connected to the DGs are more. Thus the stress on the DGs in the island is reduced by proposed two stage GA algorithm.

\subsection{Bus System with 4 DGs}

For the given scenario the optimal locations of DGs obtained are at bus numbers 67, 35, 46 and 64 with capacities as $472 \mathrm{~kW}, 25 \mathrm{~kW}, 49 \mathrm{~kW}$ and $444 \mathrm{~kW}$ respectively for $W_{1}=1$. When $W_{2}$ is considered as 1 or 0.75 the optimal locations of DGs obtained are 67, 35, 45 and 64. However when $W_{l}$ is considered as 0.75 the DG sizes obtained are $422 \mathrm{~kW}, 27 \mathrm{~kW}, 53 \mathrm{~kW}$ and $469 \mathrm{~kW}$ respectively. But for $W_{2}$ $=1$ the ratings of DGs obtained are $439 \mathrm{~kW}, 25 \mathrm{~kW}, 51 \mathrm{~kW}$ and $475 \mathrm{~kW}$ respectively. The system gets islanded at bus 10 for an overload of $13.35 \%$ forming a main system consisting of buses 1-9, 28-65 and an islanded system consisting of buses 10-27, 65-69. The DG presence in the islanded network reduces the impact of islanding. 
Table 3. Comparison of results for 69 bus with 4 DGs

\begin{tabular}{|c|c|c|c|c|c|}
\hline Case & $\begin{array}{l}\text { Minimum Voltage in the system } \\
\text { (p.u) }\end{array}$ & $\begin{array}{c}\text { Voltage stability improvement } \\
(\%)\end{array}$ & $\begin{array}{c}\text { Total Active Power Loss } \\
\text { (MW) }\end{array}$ & $\begin{array}{c}\text { Reduction in Active Power } \\
\text { Loss }(\%) \\
\end{array}$ & $\begin{array}{c}\text { Islanded } \\
\text { bus }\end{array}$ \\
\hline Without DG & 0.9104 & - & 0.2056 & - & - \\
\hline Case1 & 0.9874 & 2.41 & 0.03346 & 85.79 & 10 \\
\hline Case2 & 0.9871 & 2.38 & 0.03286 & 86.23 & 10 \\
\hline Case3 & 0.9864 & 2.31 & 0.03275 & 86.84 & 10 \\
\hline
\end{tabular}

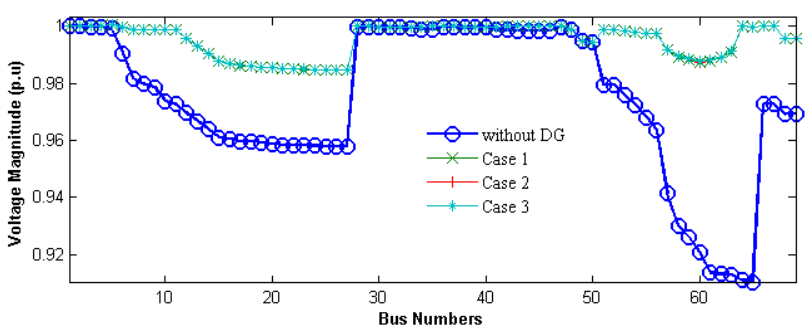

Fig. 8. Comparison of voltage profiles of 69 bus system with 4 DGs

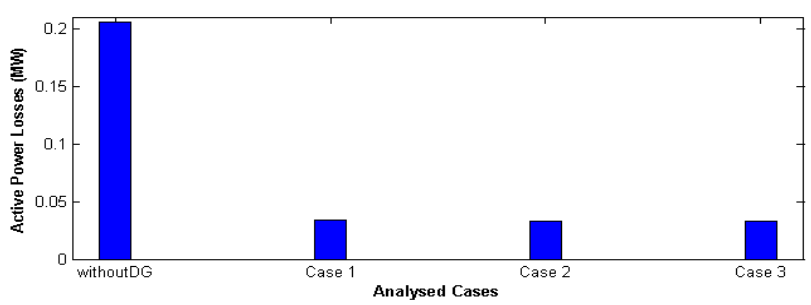

Fig. 9. Comparison of real power losses of 69 bus system with 4 DGs

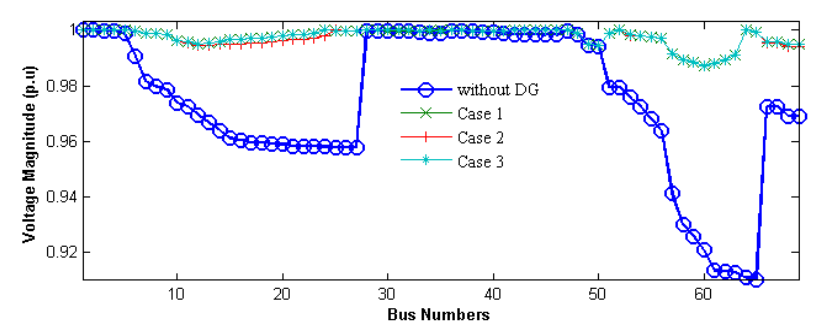

Fig. 10. Comparison of Voltage Profiles of 69 Bus system with 5 DGs

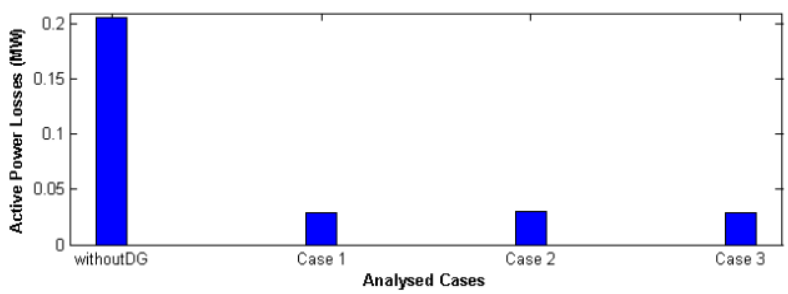

Fig. 11. Comparison of real power losses of 69 bus system with 5 DGs

Table 4. Comparison of results for 69 bus with 5 DGs

\begin{tabular}{c|c|c|c|c|c}
\hline Case & $\begin{array}{c}\text { Minimum Voltage in the system } \\
(\mathrm{p} . \mathrm{u})\end{array}$ & $\begin{array}{c}\text { Voltage stability improvement } \\
(\%)\end{array}$ & $\begin{array}{c}\text { Total Active Power Loss } \\
(\mathrm{MW})\end{array}$ & $\begin{array}{c}\text { Reduction in Active Power } \\
\text { Loss }(\%)\end{array}$ & $\begin{array}{c}\text { Islanded } \\
\text { bus }\end{array}$ \\
\hline Without DG & 0.9104 & - & 0.2056 & - \\
\hline Case1 & 0.9874 & 2.41 & 0.03017 & \\
\hline Case2 & 0.9870 & 2.38 & 0.02935 & \\
\hline Case3 & 0.9865 & 2.35 & 0.02930 & 85.33 \\
\hline
\end{tabular}

An analysis of the scenarios is presented in Table 3 . From, the table it can be observed that, when a single objective is considered for reducing the losses, the results are much better.

From Fig. 8 it can be seen that, the voltage stability margin improves when $W_{l}$ is not taken as zero. From Fig. 9 it is shown that the losses are reduced appreciably when $W_{2}$ is taken as 1 .

\subsection{Bus System with 5 DGs}

The optimal locations of DGs obtained from the proposed scheme are at bus numbers 24,35,45,52 and 64 with ratings as $200 \mathrm{~kW}, 25 \mathrm{~kW}, 50 \mathrm{~kW}, 240 \mathrm{~kW}$ and $460 \mathrm{~kW}$ respectively when $W_{1}$ is considered as 1 . When $W_{2}$ is considered as 1 the optimal locations of DGs obtained are $24,34,45,52$ and 64 with ratings as $230 \mathrm{~kW}, 25 \mathrm{~kW}, 51 \mathrm{~kW}$, $233 \mathrm{~kW}$ and $459 \mathrm{~kW}$ respectively. However, When $W_{l}$ is considered as 0.75 the optimal locations of DGs obtained are $25,34,45,52$ and 64 with ratings as $212 \mathrm{~kW}, 25 \mathrm{~kW}$, $51 \mathrm{~kW}, 227 \mathrm{~kW}$ and $465 \mathrm{~kW}$ respectively. The system gets islanded at bus 56 for an overload of $13.35 \%$ forming a main system consisting of buses 1-55, 65-69 and an islanded system consisting of buses 56-65. The DG presence at bus 64 reduces the impact of islanding.

From Figs. $10 \& 11$, it is clear that the minimum voltage in the system is increased and there is appreciable reduction in active power losses when the DGs are placed simultaneously for voltage profile improvement and loss reduction. An analysis of the scenarios is presented in Table 4. From the table, it can be seen that, when multiple objectives are considered, the loss reduction is more and the minimum voltage in the system also improves a lot.

\subsection{Bus System with 6 DGs}

The optimal locations of DGs obtained for this case are $24,34,45,52,64$ and 69 for all combinations of weights. But 
Table 5. Comparison of results for 69 bus with 6 DGs

\begin{tabular}{c|c|c|c|c|c}
\hline Case & $\begin{array}{c}\text { Minimum Voltage in the } \\
\text { system (p.u) }\end{array}$ & $\begin{array}{c}\text { Voltage stability } \\
\text { improvement (\%) }\end{array}$ & $\begin{array}{c}\text { Total Active Power Loss } \\
\text { (MW) }\end{array}$ & $\begin{array}{c}\text { Reduction in Active } \\
\text { Power Loss (\%) }\end{array}$ & $\begin{array}{c}\text { Islanded } \\
\text { bus }\end{array}$ \\
\hline Without DG & 0.9104 & $-z$ & 0.2056 & - & - \\
\hline Case1 & 0.9880 & 2.48 & 0.02716 & 86.79 & 56 \\
\hline Case2 & 0.9879 & 2.47 & 0.02634 & 87.19 & 57 \\
\hline Case3 & 0.9877 & 2.45 & 0.02614 & 87.29 & 57 \\
\hline Existing Method [6] & - & - & 0.0280 & 86.38 & 6 \\
\hline
\end{tabular}

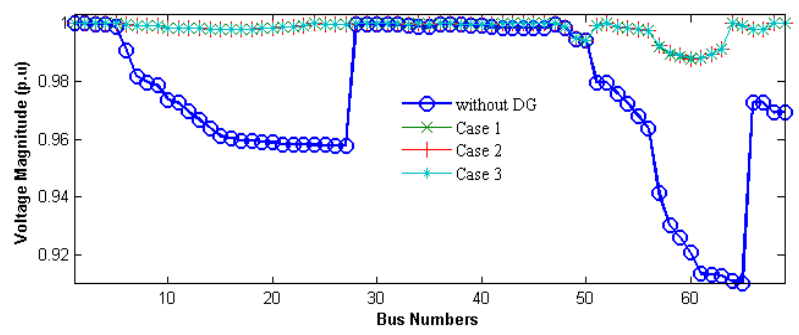

Fig. 12. Comparison of Voltage Profiles of 69 Bus System with 6 DGs and without DG

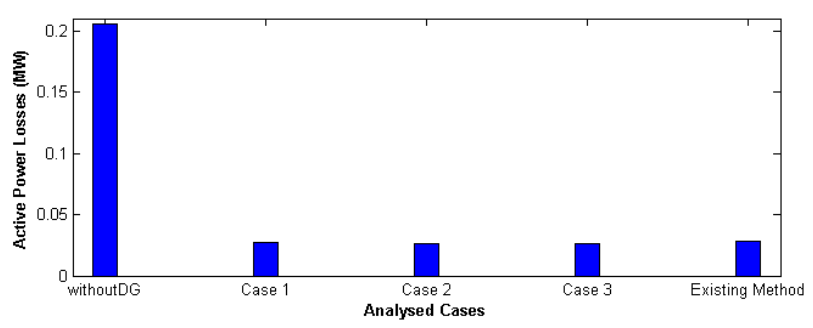

Fig. 13. Comparison of real power losses of 69 bus system with 6 DGs

different capacities are obtained for various combinations of weights as follows: (i) When $W_{l}$ is considered as 1 the ratings are $188 \mathrm{~kW}, 25 \mathrm{~kW}, 50 \mathrm{~kW}, 236 \mathrm{~kW}, 463 \mathrm{~kW}$ and $25 \mathrm{~kW}$ respectively. (ii) When $W_{2}$ is taken as 1 the ratings of DGs obtained are as $204 \mathrm{~kW}, 25 \mathrm{~kW}, 51 \mathrm{~kW}, 237 \mathrm{~kW}, 513 \mathrm{~kW}$ and $26 \mathrm{~kW}$ respectively. (iii) When $W_{l}$ is considered as 0.75 the ratings of DGs obtained are $204 \mathrm{~kW}, 25 \mathrm{~kW}, 51 \mathrm{~kW}$, $237 \mathrm{~kW}, 513 \mathrm{~kW}$ and $26 \mathrm{~kW}$ respectively. When $W_{l}=1$, the system gets islanded at bus 56 for an overload of $15.25 \%$ forming a main system consisting of buses 1-55, 65-69 and an islanded system consisting of buses 56-65. In the remaining cases, the system gets islanded at bus 57 for an overload of $13.35 \%$ forming a main system consisting of buses 1-56, 65-69 and an islanded system consisting of buses 57-65. Since the DGs are connected in the islanded network in both the cases thus it supply the active power in the island.

From Fig. 12, the voltage stability margin is improved when $W_{l}$ is considered as 0.75 . The losses are marginally reduced when $W_{2}$ is considered as 1 than when considered as 0.25 , which can be seen from Fig. 13. An analysis of the scenarios is presented in Table 5. It is evident from the table that, even though losses are greatly reduced by considering a single objective function, by considering

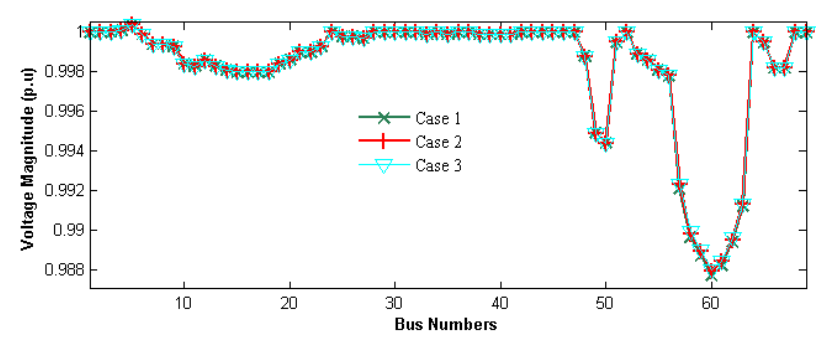

Fig. 14. Comparison of voltage profiles of 69 bus system with effect of DG for different weights

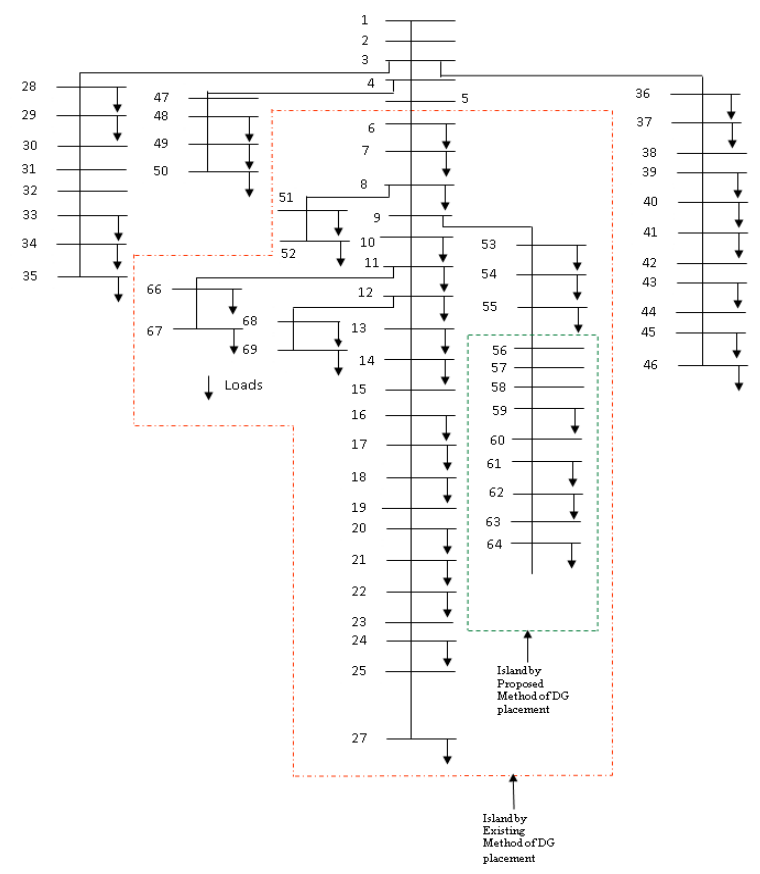

Fig. 15. Formation of Island in 69 Bus System by existing [6] and proposed method of DG placement

different weights for $W_{1}$ and $W_{2}$ the loss reduction is also appreciable with very good improvement in voltage stability margin.

The losses are appreciably reduced with the placement of the $6^{\text {th }} \mathrm{DG}$ in the system. With the increase in number of DGs the overall penetration of the DGs is reduced and the number of buses in the island is greatly reduced thereby increasing the number of buses connected to the grid.

The results have been compared with the existing method [6]. The Fig. 13 shows the formation of islands by the proposed method and existing method. It is seen that in 
existing method the islanding occurs at bus 6 for same operating conditions. The existing method of DG placement increases the stress on the DG by connecting more loads to the DGs. The proposed two stage GA algorithm reduces the stress on the DGs in the island. Fig. 14 shows the effect of weights on voltage profiles after DG placement in the 69 bus system.

\section{Conclusions}

In this paper, a two stage GA based optimal siting and sizing of DG is proposed to reduce the effect of islanding by simultaneously improving the overall voltage profile and reducing the total active power loss in individual island. The system is divided into zones for reducing the search space for optimal siting and sizing of DG in the system. The division of systems into zones allows the placement of smaller capacity DGs throughout the system rather than a single DG of larger capacity. In a two stage GA based optimization, at first stage, the weaker solutions are neglected and the fitter values are taken for the crossover and mutation in the second stage. This results in better quality of solutions and faster convergence of the results. Moreover, the allocation of DG based on the zones is much effective than opening the entire search space for the allocation of DG in the network.

However, in the event of unstable islands due to power mismatch in any island, proper control measures have to be implemented to maintain system stability.

\section{References}

[1] Thomas Ackermann, Goran Andersson, and Lennar Soder, "Distributed Generation: a definition," Electric Power Syst. Res., vol. 57, pp. 195-204, Dec 2000.

[2] W. El-Khattam, M.M.A. Salama, "Distributed generation technologies, definitions and benefits," Electric Power Syst. Res. 2004, vol. 71, pp. 119-128, Jan 2004.

[3] EU Commission Task Force for Smart Grids, Functionalities of smart grids and smart meters. Dec 2010 [Online].

[4] M.M. Aman, G.B. Jasmon, A.H.A. Bakar, H. Mokhlis, "A new approach for optimum DG placement and sizing based on voltage stability maximization and minimization of power losses," Energy Conversion and Management vol.70, pp. 202-210, April 2013.

[5] S. Gopiya Naik, D.K. Khatod, M.P. Sharma, "Optimal allocation of combined DG and capacitor for real power loss minimization in distribution networks," Electrical Power and Energy Systems vol. 53, pp. 967-973, June 2013.

[6] R. Srinivasa Rao, K.Ravindra, K.Satish and S.V.L Narasimham, "Power Loss Minimization in Distribution System Using Network Reconfiguration in the Presence of Distributed Generation," IEEE Trans. on
Power Syst., Vol. 28, no. 1, pp. 317-325, Feb. 2013.

[7] Y. Mohamed Shuaib, M. Surya Kalavathi and C. Christober Asir Rajan, "Optimal Reconfiguration in Radial Distribution System Using Gravitational Search Algorithm," Electric Power Components and Systems, vol.42, pp.703-715, April 2014.

[8] Caisheng Wang and M.Hashem Nehrir, “Analytical Approaches for Optimal Placement of Distributed Generation Sources in Power Systems," IEEE Trans. Power Syst., vol. 19, No. 4, pp. 2068-2076, Nov. 2004.

[9] Pavlos S. Georgilakis and Nikos D. Hatziargyriou, "Optimal Distributed Generation Placement in Power Distribution Networks: Models, Methods, and Future Research," IEEE Trans. On Power Systems., Vol 28, No.3, pp.3420-3428, August 2013.

[10] K. Balamurugan, Dipti Srinivasan, Thomas Reindl, "Impact of Distributed Generation on Power Distribution Systems," Energy Procedia 25 (2012), PV Asia Pacific Conference 2011, pp. 93-100.

[11] Hasan Hedayati, S. A. Nabaviniaki and Adel Akbarimajd, "A Method for Placement of DG Units in Distribution Networks," IEEE Trans. on Power Delivery., vol. 23, no. 3, pp.1620-1628, July. 2008.

[12] Vinicius F. Martins and Carmen L. T. Borges, "Active Distribution Network Integrated Planning Incorporating Distributed Generationand Load Response Uncertainties," IEEE Trans. On Power Systems, Vol. 26, No. 4, pp. 2164-2172, November 2011.

[13] Zhipeng Liu, Fushuan Wen, and Gerard Ledwich, "Optimal Siting and Sizing of Distributed Generatorsin Distribution Systems Considering Uncertainties," IEEE Trans. on Power Delivery., vol. 26, no. 4, pp. 2541-2551, October 2011.

[14] Ali Nasri, M. E. Hamedani Golshan and S. Mortaza Saghaian Nejad, "Optimal planning of dispatchable and non-dispatchable distributed generation units for minimizing distribution system's energy lossusing particle swarm optimization," Int. Trans. Electr. Energ. Syst.;vol. 24, pp. 504-519, April 2014.

[15] Duong Quoc Hung, N. Mithulananthan, Kwang Y. Lee, "Optimal placement of dispatchable and nondispatchable renewable DG units in distribution networks for minimizing energy loss," Electric Power and Energy Systems, vol. 55, pp. 179-186, February 2014.

[16] D.H. Popovic, J.A. Greatbanks, M. Begovic and A. Pregelj, "Placement of distributed generators and reclosers for distribution network security and reliability," Electrical Power and Energy Systems vol.27, pp. 398-408, February 2005.

[17] Carmen L.T. Borges and Djalma M. Falcao, "Optimal distributed generation allocation for reliability, losses and voltage improvement," Electrical Power and Energy Systems, vol. 28, pp. 413-420, February 2006.

[18] Nguyen Cong Hien, Nadarajah Mithulananthan and 
R. C. Bansal, "Location and Sizing of Distributed Generation Units for Loadabilty Enhancement in Primary Feeder,' IEEE Systems Journal, Vol. 7, no. 4, pp 797-806, December 2013.

[19] M.M. Aman, G.B. Jasmon, A.H.A. Bakar and H. Mokhlis, "Optimum network reconfiguration based on maximization of system loadability using continuation power flow theorem," Electrical Power and Energy Systems vol. 54, pp.123-133, January 2014.

[20] Po-Chen Chen, Reynaldo Salcedo, Qingcheng Zhu, Francisco de Len, Dariusz Czarkowski, Zhong-Ping Jiang, Vitaly Spitsa, Zivan Zabar and Resk Ebrahem Uosef "Analysis of Voltage Profile Problems Due to the Penetration of Distributed Generation in LowVoltage Secondary Distribution Networks", IEEE Trans. on Power Delivery, vol. 27, no. 4, pp 20202028, October 2012.

[21] "IEEE Application Guide for IEEE Std 1547, IEEE Standard for Interconnecting Distributed Resources With Electric Power Systems, ", 2008.

[22] J. Yin, L. Changand C. Diduch,"Recent developments in islanding detection for distributed power generation,'Proc. Large Engineering Systems Conf. Power Engineering, pp 124-128, Jul. 2004.

[23] H.H. Zeineldin and James L.Kirtley, Jr., "A Simple Technique for Islanding Detection with Negligible Nondetection Zone," IEEE Trans. On Power Delivery, vol. 24, no. 2, pp 779-786, April 2009.

[24] H. Laaksonen, "Advanced Islanding Detection Functionality for Future Electricity Distribution Networks," IEEE Trans. On Power Delivery, vol.28, no.4, pp 2056-2064, October 2013.

[25] Khalil El-Arroudi, Gza Jos, Innocent Kamwa and Donald T.McGillis “ Intelligent- Based Approach to Islanding Detection in Distributed Generation", IEEE Trans. On Power Delivery, vol. 22, no. 2, pp. 828835, April 2007.

[26] S. P. Chowdhury, S. Chowdhury, P. A. Crossley, "Islanding protection of active distribution networks with renewable distributed generators: A comprehensive survey," Electric Power Systems Research 79 (2009) 984-992, February 2009.

[27] A. Shahmohammadi, M.T. Ameli, "Proper sizing and placement of distributed power generation aids the intentional islanding process," Electric Power Systems Research vol.106, pp.73-85, January 2014.

[28] D.E. Goldberg, "Genetic algorithm in search, optimization, and machine learning". New York: AddisonWesley 1989.

[29] P. Chiradeja and R. Ramkumar, "Voltage profile improvement with distributed wind turbine generation-a case study," in Proc. 2003 IEEE PES General Meeting, vol. 4 pp. 2331-2336.

[30] T.Q.D. Khoa, P.T.T. Binh and H.B.Tran, "Optimizing location and sizing of distributed generation in distribution systems," in Proc.2006 IEEE PES Power
Syst. Conf. Expo., pp 725-732, November 2006.

[31] T.Gozel and M.H.Hocaoglu, "An analytical method for sizing and siting of distributed generators in radial systems," Elect. Power Syst. Res. Vol. 79, pp. 912-918, Jun. 2009.

[32] G. Celli, E. Ghiani, S. Mocci and F. Pilo, "A multiobjective evolutionary algorithm for the sizing and siting of distributed generation," IEEE Trans. Power Syst., vol. 20, no. 2, pp. 750-757, May 2005.

[33] The Math Works, Inc., MATLAB programming, 2008.

[34] Federico Milano, “An Open Source Power System Analysis Toolbox," IEEE Trans. On Power Syst., Vol. 20, No. 2, pp. 1199-1206, Aug 2005.

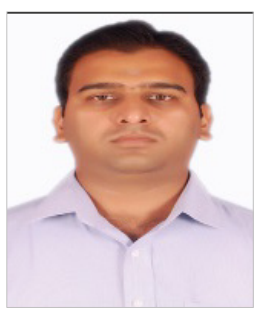

Narayanan. K He received his B.E. in Electrical and Electronics engineering from Anna University, Chennai in 2008 and M.Tech in Power Systems from Malaviya National Institute of Technology, Jaipur (Rajasthan) in 2008. Presently, he is pursuing his Ph.D. degree at Malaviya National Institute of Technology, Jaipur (Rajasthan), India. His areas of research interests are power system planning and operation, AI applications to the power systems.

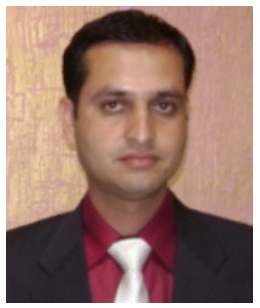

Shahbaz A. Siddiqui received his B.E. in Electrical and Electronics Engineering from Karnataka University, Dharwad in 2000, M.Tech in Power Systems from Malaviya National Institute of Technology, Jaipur (Rajasthan) in 2006 and $\mathrm{Ph} . \mathrm{D}$. in Electrical Engineering from Malaviya National Institute of Technology, Jaipur (Rajasthan) in 2015. Presently, he is working as an Associate Professor in Manipal University, Jaipur (Rajasthan), India. His areas of research interests are power system dynamics and control, AI applications to the power systems.

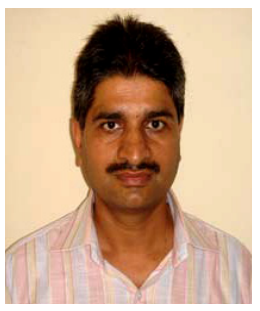

Manoj Fozdar received his B.Sc. (Engg.) in Electrical Engineering and M.Sc.(Engg.) in Power System and Drives from Aligarh Muslim University, Aligarh in 1989 and 1992 respectively, and Ph.D. in Electrical Engineering from Rajasthan University, Jaipur in 2007. Presently he is working as Professor in Electrical Engineering Department at Malaviya National Institute of Technology, Jaipur (Rajasthan), India. His areas of research interest are power system operation and control \& FACTS. 